\title{
A solas con una educadora de museos: Una conversación sobre su trabajo, situación y visión de la educación artística contemporánea ${ }^{1}$
}

\author{
Eneritz López Martínez ${ }^{2}$ \\ Eva Alcaide Suárez ${ }^{3}$
}

\section{Resumen}

¿Por qué caminos transita actualmente la educación artística en los museos?, ¿cuál es la formación y situación profesional de las educadoras de museos?, ¿qué tipo de relaciones se establecen entre educadoras de arte y docentes? A través de una conversación directa y sincera, una experimentada educadora y una investigadora universitaria explorarán estas y otras cuestiones relacionadas con las prácticas pedagógicas actuales en los museos de arte. Al hilo de los relatos personales en los que compartirán sus experiencias, anhelos y percepciones, irán exponiendo también diversas reflexiones intercaladas con las visiones de diferentes expertos y referentes teóricos en este ámbito.

Palabras clave: educadora de museo, precariedad laboral, falta de reconocimiento, formación continúa.

\begin{abstract}
Which paths is art education in museums going through? What are the requirements and professional situation of museum educators? What kinds of relationships exist between art educators and school teachers? Through a direct and sincere conversation, an experienced educator and a researcher will explore these and other issues related to the pedagogical practice in art museums. Following the thread of these personal reports where they will share their experiences, desires and perceptions-, some reflections will be presented, interspersed with some quotes and views by diverse experts on this field.
\end{abstract}

Key words: museum educator, precarious employment, lack of recognition, lifelong learning.

\footnotetext{
${ }^{1}$ Este artículo surge de las reflexiones compartidas entre una investigadora y una educadora de arte, tras haber trabajado colaborativamente en un proyecto de investigación relativo a la formación, situación y profesionalización de las educadoras de museos. Este texto está formado por un cúmulo de conversaciones entre ambas donde analizan desde un punto de vista crítico sus experiencias vividas y saberes en relación al complejo campo de la educación en museos.

2 Doctora en Educación Artística por la Universidad de Barcelona y Licenciada en Historia del Arte (Universidad del País Vasco). Fruto de sus investigaciones ha realizado varias publicaciones sobre la formación, situación y profesionalización de las educadoras de museos. Su actividad profesional reciente se centra en el diseño, gestión e implementación de proyectos pedagógicos en instituciones culturales y en la redacción de materiales divulgativos relacionados con la práctica artística.

${ }^{3}$ Licenciada en Historia del Arte por la Universidad de Valladolid, cuenta también con un Postgrado de Educador de Museos de la Universidad de Zaragoza. Durante los últimos años ha trabajado como educadora de arte en diversas instituciones museísticas. Actualmente presta sus servicios en los departamentos de educación de varios museos vallisoletanos, dedicándose tanto al diseño como a la ejecución de programas pedagógicos de diversa índole.
} 


\section{Prólogo}

¿Por qué caminos transita actualmente la educación artística en los museos?, ¿cuál es la formación y situación profesional de las educadoras ${ }^{4}$ de museos?, ¿qué tipo de relaciones se establecen entre educadoras de arte y docentes? Ante la dificultad de contestar de manera amplia y generalizada a estas preguntas -debido, entre otras cosas, a la indefinición del ámbito laboral de la educación museística-, hemos decidido aportar nuestra visión personal al respecto a través de una conversación entre nosotras sobre los asuntos que más nos preocupan de esta área de trabajo. Por ello, a pesar de que este texto tiene formato de entrevista, se trata de un artículo construido y consensuado entre ambas autoras, quienes no hemos tenido en esta ocasión papeles de investigadora e informante respectivamente ${ }^{5}$. Nuestra intención con este tipo de texto dialógico es mostrar la realidad y circunstancias de un caso específico, a partir del cual poder contextualizar las problemáticas que pueden ser fácilmente compartidas por la comunidad de educadoras de museos. Lo que hemos pretendido es comprender una situación concreta, ya que pensamos que "las generalizaciones sobre las experiencias humanas resultan casi siempre problemáticas" (VAN MANEN, 2003:40).

Nuestras trayectorias profesionales - una forjada en los departamentos de educación de varios museos de arte y otra vinculada a la investigación desde la universidad- tienen en común un vasto conocimiento del papel y situación laboral de las educadoras de museos. Por ello, las temáticas sobre las que hemos articulado nuestro diálogo son: cómo se llega a ser educadora de museos y de qué maneras se aprende esta incierta profesión, dónde reside la validez y reconocimiento de su trabajo diario, cuál es su situación laboral y sus expectativas de desarrollo profesional y hasta qué punto se relaciona con el profesorado. Pero, cuando una está a gusto conversando y se siente especialmente comprometida con los temas que está tratando, la charla va fluidamente saltando de un tema a otro casi sin quererlo, así que a continuación presentamos este cúmulo de opiniones, percepciones y visiones de nuestra realidad.

\footnotetext{
${ }^{4}$ A lo largo del texto usaremos el femenino genérico "educadora" ya que la mayoría de las personas que ejercen labores educativas en los museos son mujeres. En ningún caso queremos que se entienda esta utilización del término en femenino como excluyente hacia los educadores, es simplemente una cuestión de sentido común y justicia en la representación de lo que estamos relatando.

${ }^{5}$ Sin embargo, este papel sí que lo tuvimos durante uno de los estudios de caso incluidos en la tesis doctoral: LÓPEZ, E. (2009) “¿Profesionales de la educación en el museo?: Estudio sobre la formación y la profesionalización de los educadores de museos españoles" [tesis doctoral], Universidad de Barcelona
} 
I nercias, vocaciones y oportunidades: cómo se llega a ser educadora de museos

“La investigación es un acto de preocupación” (VAN MANEN, 2003:24).

Pregunta: ¿Cómo, cuándo y por qué decidiste comenzar a trabajar como educadora de museos?

Respuesta: No guardo entre mis recuerdos la mínima idea de que yo decidiese en ningún momento ser educadora de museos. Es más, mientras estudiaba la licenciatura de Historia del Arte, no tenía ni la menor sospecha de que hubiera una profesión llamada así y mucho menos sabía cuáles podían ser sus funciones. Ante la desesperación de tener que seguir formándome después de terminar mi carrera universitaria para conseguir un puesto de trabajo acorde con mis estudios, me incliné por hacer algún master o postgrado en relación con los museos. Cuando terminé de estudiar en la universidad era tal la desorientación que tenía y la preocupación por mi futuro laboral, que el desconcierto y la inestabilidad me hicieron deambular -con muchas incertidumbres- por muchas opciones pensando cuál sería la que me garantizara un camino profesional motivador. $Y$ eso no era fácil, y efectivamente no lo fue. Tras varios meses de dudas decidí realizar el “Postgrado en Educador de Museos” de la Universidad de Zaragoza (España), siendo ésta la primera vez que escuchaba tal denominación. Ese nombre despertó mi curiosidad. Éste es, entonces, el punto de partida de mi interés por la educación en los museos. A partir de entonces realicé diversas prácticas en los departamentos de educación de varios museos $\mathrm{y}$, cuando regresé a Valladolid -mi ciudad de origen-, empecé a trabajar en algunas exposiciones haciendo de guía o monitora, siempre transmitiendo lo que otros ya habían pensado que debía decir. Eran otros tiempos y en aquellos momentos yo no me llegué nunca a plantear que esto se podía cambiar y que yo podía construir mi propio discurso. Cuando estás dentro de una institución las inercias y el bloqueo intelectual al que te someten son a menudo tan evidentes que parecen formar parte de la política de la empresa, hasta el extremo incluso de hacerte creer que como educadora no puedes pensar por ti misma, sino que has de limitarte a repetir. En aquel tiempo yo no me cuestionaba nada, ni lo más mínimo, ya que eran los propios engranajes del sistema los que se encargaban de hacerlo por mí. En resumen, éste fue el comienzo de mi vida laboral en el ámbito de la "educación en museos".

Nos ha interesado comenzar la conversación con esta cuestión, ya que hemos constatado que "la mayoría de los profesionales que están trabajando cara a cara con el público desde los museos, no tiene o tiene muy pocas nociones sobre educación artística, y éste es un problema muy serio. Otro problema: ¿cómo se accede a ser "educadora de 
museo"?, ¿se accede mediante una oposición, por medio de un contrato, o basta un currículum que demuestre haber trabajado antes en otros museos?, ¿cómo se elige a los directores de los departamentos de educación?, ¿provienen de otros departamentos y recalan en este, o son profesionales altamente cualificados, especialistas en esta materia y no en otras?" (ACASO, 2007:78). Muchas de estas problemáticas están hoy a la orden del día y tienen difícil solución debido a la invisibilidad e indefinición del trabajo educativo en museos, considerado aún una "semiprofesión".

Según una investigación realizada en una veintena de museos y centros de arte españoles, la mayoría del personal que se dedica a labores educativas proviene de la carrera de Historia del Arte y, en menor medida, también de Historia o Geografía, titulaciones que no incluyen ninguna materia relacionada con la pedagogía (MESÍAS, 2008). Aunque peligrosamente común, esta situación no deja de ser contradictoria. A este respecto, nos parecen muy pertinentes las siguientes preguntas, sobre las que deberíamos reflexionar y que nos dan pistas sobre la gravedad de la situación que estamos analizando: “¿Cuántos especialistas en, pongamos por caso, psicología o didáctica trabajan en nuestros museos? ¿Qué conocimientos tienen los que bregan todos los días con el público acerca de etapas de aprendizaje, psicología de la percepción o procesos cognitivos? ¿Qué saben sobre el público, sobre sus anhelos, sobre sus expectativas? ¿Cómo se comportan ante los imprevistos o las preguntas a las que no saben responder? ¿En qué medida participan en la planificación de las actividades del museo y en su materialización - por ejemplo en el montaje y elaboración de recursos auxiliares de la exposición?" (DÍ AZ, 2008: 145-146).

Pregunta: ¿Qué aspectos de tu formación rescatas para tu práctica diaria?

Respuesta: A día de hoy, rescato toda mi formación posterior a mis experiencias académicas. Llevo muchos años dedicando mis horas y mi tiempo libre a leer sobre educación artística, educación en museos, viajando a congresos y cursos (incluso participando activamente en muchos de ellos) y, sobre todo, a relacionarme con gente dentro de este ámbito con la que comparto intereses y actitudes. Tengo muchos colegas dentro del campo de la educación tanto en museos como en la universidad y son ellos y ellas las que me proporcionan con sus trabajos, proyectos y experiencias muchos aspectos que luego yo reciclo, interiorizo y fusiono a mi propia experiencia y a mi manera de entender mi práctica diaria.

Pregunta: ¿Qué otras cosas crees tú que necesitarías para desarrollar mejor tu trabajo?, ¿por qué? 
Respuesta: Necesitaría ubicarme dentro de un ámbito profesional situado en el estatus que se merece, es decir, igualado al resto de los campos profesionales presentes en un museo. Los departamentos de educación siguen siendo la oveja negra dentro del organigrama de un museo, y creo que no deberían estar supeditados a otros departamentos ni las educadoras deberíamos depender de otros perfiles profesionales. De hecho, la labor educativa es concebida como la repetición del discurso del comisario o de los artistas con lo que se menosprecia constantemente nuestra labor como educadoras. Por otro lado me parecen absurdas las competiciones sobre las cifras de visitantes de algunos centros para los que trabajo no importándoles tanto la calidad como la cantidad. Según esta "política de la cantidad" es más importante que un número elevado de gente entre al museo que ofrecer un programa educativo de calidad con propuestas interesantes.

Como vemos, desde la propia práctica se pone de manifiesto que la formación continua de las educadoras en nuestros museos es limitada y que ello muchas veces les lleva a no tener herramientas para manejar muchas de las situaciones que su trabajo les plantea cotidianamente. Por eso - y gracias a que mantienen una positiva actitud de aprendices constantes- deben formarse una vez ya en la práctica por medios tan dispares como la asistencia a cursos, jornadas, congresos (donde no siempre se cumplen sus expectativas de aprendizaje) o siendo autodidactas, es decir, buscando por sí mismas bibliografía, hablando con profesores de materias afines a su campo de acción o intercambiando experiencias e información con otros profesionales del ámbito. Este sobreesfuerzo refleja, además de su voluntad por desarrollarse intelectualmente, el compromiso que normalmente tienen con su actividad.

Por otro lado, está bastante extendida -y legitimada desde numerosos foros, tanto vinculados a ámbitos universitarios como museísticos- la idea de que a ser educadora se aprende sólo desde la experiencia, lo que resta peso a sus reivindicaciones laborales y pone cortapisas a sus expectativas de formación continua. En este sentido, aunque las "educadoras saben que muchas de las cosas que mejor se han enseñado no se podían programar en un papel o ser preconcebidas dentro de un determinado sistema" (AYUSTE et al., 2005: 77), reconocen que el conocimiento adquirido a través de la experiencia, aunque importante, es insuficiente para satisfacer las demandas profesionales. En resumen, a pesar de valorar enormemente su aprendizaje experiencial, las educadoras son conscientes de que su profesión no puede ser aprendida sólo desde la práctica. 
Pregunta: ¿En qué consiste tu trabajo diario exactamente?, ¿por qué crees que es valioso?

Respuesta: El grueso de mi trabajo consiste en proporcionar a los grupos que visitan el museo -ya sean escolares o adultos- herramientas con las que construir sus propios significados ante el hecho artístico basados en sus experiencias, actitudes e intereses. La idea es que piensen, razonen, generen conocimientos. Me resulta casi imposible enseñar que en el arte nada es seguro, que todo es cuestionable por lo que la incertidumbre y la imaginación deberían formar parte de nuestra vida cotidiana. Pero contar con estas premisas se hace permanentemente dificultoso por nuestra manera de pensar, aprendida a través de una educación tradicional, convencional y llena de tópicos, donde sólo se enseñan certezas y no hay lugar para dudas ni ambigüedades. Romper con estas barreras y otras resistencias naturales de cada contexto son parte del terreno que trabajo pero igualmente es difícil llevarlo a cabo porque desde las instituciones no se respalda una educación que cuestione, que sea crítica y que elabore un discurso no afirmativo. Por todo esto creo que mi trabajo puede ser muy valioso. Es una lástima que en muchos sitios la norma implícita de la educación no sea pensar, sino formar individuos alineados y dependientes de un sistema que se empeña en crear personas que no piensen por sí mismas y que no sean consecuentes con sus decisiones.

Las educadoras han jugado un papel imprescindible en los museos haciendo que estos sean más sensibles a los intereses y necesidades de los públicos, siendo además las encargadas de interpretar las colecciones, permitiendo además que los visitantes aporten sus miradas (ROBERTS, 1997). De hecho, uno de los aspectos mejor valorados de su trabajo es justamente que trabajan directamente con el público, recogiendo sus demandas, sus visiones, sus preferencias y respondiendo ante ello. Este contacto continuo con los usuarios hace que las educadoras sean las primeras en identificar las barreras que mantienen al público alejado del museo y son capaces de identificar los problemas subyacentes, convertirlos en retos e improvisar soluciones (Munley, 1999, en ANDERSON, 2004). Su trabajo puede ser resumido diciendo que desarrollan, implementan, evalúan y supervisan los programas educativos del museo con la finalidad de facilitar el acceso del público a las colecciones y otros recursos (VAN MENSCH, 1989). Sin embargo, en muchas ocasiones su trabajo queda reducido a la parte de ejecución, mientras que la parte de diseño y evaluación son cometido de gestores, programadores, coordinadores o personal externo. Tanto es así que comúnmente las educadoras de museos "son consideradas profesionales funcionales, a veces dedicadas al hacer, otras conocedores de estrategias para la instrucción y la psicología educativa, el marketing y las relaciones públicas" (PADRÓ, 2005). 
Pregunta: ¿Cuáles son los aspectos que consideras más positivos de tu trabajo?

Respuesta: Por un lado la honestidad de enseñar formas diferentes de pensar, de despertar el deseo de aprender y de generar conocimiento. Por otra parte, el trabajo continuado y el proceso de formación en el que me veo inmersa por iniciativa propia para intentar estar siempre a la altura de las circunstancias que rodean mi trabajo y mis intereses. Aunque todo esto a veces sea parte de mi sueño, de mis ganas de superación $y$, sobre todo, de mi instinto de supervivencia en un campo como éste donde la motivación y las ganas de trabajar pueden ser castradas continuamente.

\section{Frágil situación laboral y expectativas pendientes de un hilo}

En términos generales, en el contexto español la situación laboral de las educadoras de museos tiende a ser bastante insegura, precaria, inestable... en fin, frágil. Es frecuente encontrarse con departamentos de educación donde hay menos personal del necesario para realizar las funciones que se le requieren, dando como resultado educadoras sobreocupadas que nunca encuentran tiempo para reflexionar sobre su trabajo, formarse o desarrollar aspectos de su labor no directamente relacionados con la atención al público.

Como se pregunta Iñaki Díaz (2008), “¿por qué siempre parece que [en los museos] escasea el personal? (...) ¿y ese personal existente se recicla con periodicidad? ¿Se le gratifica y se le facilitan las cosas cuando pide asistir a un curso, a un congreso, a una reunión donde pueda ponerse al día? ¿Se le escucha cuando propone actividades, se le tiene en cuenta a la hora de tomar decisiones políticas?" (:13). Todas estas preguntas, que tratándose específicamente de las educadoras podrían ser respondidas negativamente, corroboran la situación de invisibilidad institucional y sumisión laboral en la que se encuentran actualmente las profesionales de la educación.

Un ejemplo de ello es que la mayoría son subcontratadas por Empresas de Trabajo Temporal y, por lo tanto, no hay responsabilidad por parte del museo para con ellas. Además de la subcontratación mediante una empresa externa, otras modalidades habituales de vinculación precaria de educadoras a un museo son las prácticas de licenciatura o master (poco o nada remuneradas) o la concesión de una beca (durante la cual con la excusa de realizar una formación práctica, se termina trabajando como uno más). Estas situaciones son cada vez más frecuente ya que, en la economía-red que impera en la sociedad actual, la externalización, consistente en contratar a terceros la realización de funciones de apoyo -normalmente las consideradas no fundamentales-, está a la orden del día (Rifkin, 2000). Precisamente por eso en los museos de arte, a 
menudo, las educadoras se conciben a sí mismas teniendo poco o ningún poder y estando subordinadas a otros profesionales de reconocido prestigio.

Pregunta: ¿Cómo describirías a grandes rasgos tu situación laboral?

Respuesta: De una fragilidad espantosa. Siempre he trabajado como autónoma y nunca como personal contratado. Además, el hecho de ser autónoma suele venir acompañado de inseguridad, precariedad y/o estar pendiente de subvenciones de entidades bancarias que financien el desarrollo de programas educativos y consecuentemente nuestra remuneración. Esto a las educadoras nos afecta negativamente porque no tenemos los mismos derechos ni privilegios que las personas a las que la institución les proporciona un puesto laboral. El hecho de no vincularnos formalmente con las instituciones es una manera de desprestigiar nuestra labor intelectual y de dificultar la valoración de nuestro perfil. Siempre estamos sometidas a las decisiones de otros, de esos otros que sí forman parte de la plantilla y que sí pueden decidir. Creo que en general, no existe una conciencia real de la relevancia de nuestro trabajo y por ello no existe una política de contratación que nos consolide y deje de situarnos en el escalón más bajo.

Pregunta: ¿Cuáles son tus principales expectativas laborales y qué crees que necesitarías para cumplirlas?

Respuesta: Mis expectativas a día de hoy son formar parte de un equipo de trabajo que apueste por una educación que ponga en marcha estrategias críticas -incluso radicales-, para formar personas que tengan voz, criterio y experiencias propias. Que deje de lado ese revestimiento de romanticismo que suele impregnar nuestra labor al creernos que lo que estamos haciendo está bien sin proponernos ninguna autocrítica. Para cumplirlas necesitaría rodearme de un grupo de personas que crean en un proyecto educativo crítico que se reelabore entre todos y que se pueda ir repensando y regenerando continuamente. No me parece bien que algunas personas se acomoden en puestos fijos, con una tendencia determinada, y dejen de luchar por conseguir metas y de tomar decisiones comprometidas. En estos casos, suelen relajarse y priorizar que todo siga su curso sin sobresaltos $y$, especialmente, tienden a no cuestionar absolutamente nada (para asegurar su perpetuidad en el puesto). Tampoco creo en las personas que imponen sus discursos y hacen prevalecer su forma absoluta de pensar sobre otras, amparándose en estructuras de poder perversas que siempre favorecen a quien domina y silencian a quien es dominado o subordinado. A lo largo de mi vida laboral, he vivido este tipo de de situaciones y puedo constatar las experiencias negativas que me han proporcionado algunas imposiciones injustas de esta índole. 
Pregunta: ¿Cómo crees que sois vistas las educadoras por el resto del personal que trabaja en los museos?

Respuesta: Pues debido a la no profesionalización de nuestra actividad como educadoras, creo que muchas veces somos vistas como títeres o marionetas. Por un lado, esto se debe a nuestra posición de "no profesionales" y, por otro lado, al desconocimiento de nuestra labor, que viene acompañado del prejuicio de ser consideradas meras transmisoras del discurso curatorial, es decir, que entienden que no generamos conocimiento propio sino que somos repetidoras de significados. Sí es cierto que nos ven como personas muy trabajadoras, muy involucradas con la institución y sumamente responsables, pero no como personal con una importante labor intelectual. El que se ningunee a menudo el sector educativo tiene que ver con el reflejo que proyectamos o, más bien, con el prejuicio que los demás proyectan sobre nosotras. Para cambiar esta situación sería necesario que contaran directamente con nuestra voz, nuestras experiencias y nuestras posibilidades, sin centralizar todo en coordinadores, gestores, directores o personal administrativo que sólo anhelan llevarse méritos, deslegitimando a las educadoras que normalmente son las verdaderas artífices de proyectos e ideas. Para encaminarnos hacia estos cambios sería interesante construir propuestas de acción, formación y reflexión alternativas a las instauradas en las instituciones.

Por todo lo comentado hasta el momento, y justamente para permitir que las educadoras tengan más presencia institucional y cuenten con las herramientas necesarias para construir su profesión, se debería fomentar la formación de educadoras entendidas como profesionales reflexivas (SCHÖN, 1998), cuyo desarrollo profesional no se centre sólo en la práctica, sino también en la reflexión y crítica respecto a su propia acción. Esto nos llevaría a ver a la educadora de arte como gestora, investigadora, facilitadora, interpretadora, una intelectual crítica (PADRÓ, 2005). Su papel sería así el de instigadora, enredadora, provocadora de interferencias y relaciones (AGIRRE, 2006).

\section{Apostando por estrechar vínculos entre museos y escuelas: colaboraciones entre profesorado y educadoras de museos}

Pregunta: ¿Por qué crees que es importante la educación artística en el arte contemporáneo?

Respuesta: La educación artística es una categoría que se define constantemente y en múltiples direcciones. Me interesa esa parte de la educación artística preocupada por el contexto, la comprensión de la cultura visual -que es favorecedora de interpretaciones 
más que de percepciones. No soy partidaria de utilizar la educación artística como clase de manualidades, ni como excusa para expresar sentimientos o vivencias, ni como desarrollo de técnicas vacías, todo ello en mi opinión carente de contenido intelectual, reflexión y autocrítica. Actualmente se siguen manteniendo posturas muy tradicionales y convencionales de la educación artística, por ejemplo, entendiéndola como expresión en muchos centros escolares, universidades e instituciones culturales. Considero relevante la educación artística como parte de la formación intelectual integral de las personas, buscando siempre replanteamientos de los objetos artísticos vistos como piezas con significados cambiantes y entendiéndolas en contextos de producción y recepción, en vez de analizarlas desde una mirada universalista. Considero interesantes propuestas de trabajo con escolares o adultos, donde ellos son parte del proceso de aprendizaje, donde nada está escrito ni predeterminado y por ello todo puede cambiarse y replantearse. Me interesa la educación que incorpora a los educandos como personas reflexivas y pensantes, frente a una educación que les dice qué y cómo pensar, oprimiéndoles y debilitando su capacidad de pensamiento propio y autónomo. Como educadora me sitúo en el lado opuesto de la educación transmisora. Creo que es muy importante fomentar una idea de educación artística como sinónimo de inquietud, interés, opinión, crítica, trabajo en equipo reflexivo $y$, en algunas ocasiones, radical con ciertos planteamientos.

Pregunta: ¿Qué crees que puede aportar un museo a un profesor?

Respuesta: La posibilidad de poder trabajar aspectos tanto formales como informales (del currículo) aprovechándose de los contenidos que se ofrecen desde el museo y optando por la posibilidad de trabajar con las educadoras de los departamentos de educación. Los profesores pueden abordar diferentes estrategias de comprensión vinculadas a determinados temas y problemas relacionados con su alumnado, con el contexto, y conectarlo con objetos artísticos que estén en los museos. Esto lógicamente implica un esfuerzo y una dinámica muy activa por parte del profesor, ya que entender las obras de arte como objetos producidos por una cultura y un contexto determina una forma de pensamiento sobre dónde y cómo se producen y para qué.

Pregunta: ¿Hasta qué punto consideras importante que docentes y educadoras de museos colaboren en proyectos pedagógicos conjuntos?, ¿de qué manera se podría trabajar en esta dirección?

Respuesta: Hace tiempo que me preocupa la siguiente cuestión: ¿cómo desde los departamentos de educación nos acercamos a las escuelas? Y, por otro lado, me pregunto también: ¿de qué manera podemos crear proyectos comunes que nos beneficien tanto a museos como escuelas? Desde mi experiencia he ido constatando como una inmensa mayoría de los profesores/as que visitan los museos se sienten 
preocupados porque piensan que desde los departamentos de educación no les tenemos en cuenta a la hora de programar el contenido de los programas educativos que les ofrecemos. Desde su punto de vista hay una desvinculación de los contenidos curriculares que están viendo en clase y lo que trabajamos con ellos cuando vienen al museo. Como educadora consciente de esta realidad veo urgente y necesario trabajar con propuestas educativas plurales cuya metodología sea trabajada a partir de una colaboración entre la educadora y el profesor de tal forma que lo tratado en el museo sea aprovechado en clase incorporándose al aprendizaje vital de los alumnos, no ciñéndonos así únicamente al programa académico. Desde los museos podemos completar aquellos conocimientos que en el contexto escolar no se contemplan por no estar recogidos como parte del currículo. Pero también entiendo que llevar esto a cabo supone un gran esfuerzo y mucho interés tanto por parte de profesores como de los educadores. En muchas ocasiones, las prisas, el agobio de tener que adecuarse a unos contenidos insertos en el currículo para llevar a buen puerto el curso, hacen que el profesorado no tenga el tiempo suficiente en clase para hablar de otros contenidos y de otras experiencias posiblemente mucho más atrayentes para el alumnado tales como sus gustos, su estética, la música que escuchan, sus intereses...en fin, cuestiones que normalmente no se contemplan en el colegio pero sí fuera de él.

Una vez terminada esta informal entrevista, ambas estamos de acuerdo en remarcar que especialmente enriquecedores son los vínculos que se establecen entre personal de museos, investigadores, profesores, artistas y otros profesionales cuando trabajan en proyectos colaborativos. Estas sinergias entre distintos museos, centros de arte, escuelas, asociaciones, colectivos de artistas, universidades y otras entidades permiten desarrollar programas pedagógicos abiertos y flexibles, evitando que los museos tengan que ofertar solamente la visita única, estándar y cerrada y tendiendo así a la producción de experiencias en vez de objetos. En este sentido, pensamos que se deberían empezar a generalizar los proyectos de trabajo (complejos, de larga duración, que involucran a la comunidad) que tienen en cuenta que el aprendizaje es algo que ocurre a largo plazo y no un hecho inmediato. Creemos que es precisamente creando comunidades de aprendizaje como se pueden impulsar actualmente prácticas educativas significativas y contemporáneas en los museos.

\section{Referencias}

ACASO, María (2007) “Por qué a la educación artística no le gustan los museos? Repensando los problemas actuales de la educación artística en las instituciones culturales". En: CALAF, R.; FONTAL, O. y VALLE, R. (coord.) (2007) Museos de Arte y

Educación, construir patrimonios desde la diversidad. (pp. 75-82) Gijón: TREA 
AGIRRE, Imanol (2006) "Hacia un imaginario para el futuro en educación artística", Actas del Congreso Internacional de Educación Artística y Visual, Sevilla.

ANDERSON, Gail (ed.) (2004) Reinventing the museum. Historical and contemporary perspective on the paradigm shift. Oxford: Altamira Press

AYUSTE, Ana; FLECHA, Ramón; LÓPEZ, Fernando y LLERAS, Jordi (2005) Planteamientos de la pedagogía crítica. Comunicar y transformar. Barcelona: Graó [1a edición: 1994]

Dí AZ, Ignacio (2008) La memoria fragmentada. El museo y sus paradojas. Gijón: Trea MESÍAS, José María (2008) “¿Cuál es el perfil profesional de las educadoras/es de museos de arte contemporáneo?", Actas del II Congreso Internacional de Educación Artística, Granada.

PADRÓ, Carla (2005) "Educación en museos: representaciones y discursos". En: SEMEDO, Alice y TEIXEIRA, José (2005) (coord.) Museus, discursos, representações (pp. 49-60) Oporto: Afrontamento

RIFKIN, Jeremy (2000) La era del acceso. La revolución de la nueva economía. Buenos Aires: Paidós

ROBERTS, L. (1997): From knowledge to narrative. Educators and the changing museum. Washington y Londres: Smithsonian Ins. Press

SCHÖN, Donald (1998) EI profesional reflexivo. Cómo piensan los profesionales cuando actúan. Barcelona: Paidós

VAN MANEN, M. (2003) Investigación educativa y experiencia vivida. Barcelona: Idea Books

VAN MENSCH, P. (ed.) (1989) Professionalising the muses. The museum profession in motion. Amsterdam: AHA Books Art History. 